\title{
La retórica violenta y la teoría de la neutralización en el ejercicio del derecho de reunión en España
}

\section{Violent rhetoric and neutralization theory in the exercise of the right of assembly in Spain}

Antonio Bellón Crespo ${ }^{1}$

UNED

Antoniobellocrespo@hotmail.com

Recepción: 20/12/2018 Revisión: 12/03/2019 Aceptación: 14/03/2019 Publicación: 01/06/2019

\section{Resumen}

El derecho de reunión representa una realidad socio-jurídica de máxima actualidad, pues su ejercicio se encuentra más presente que nunca en la vida de cualquier país democrático. La situación de crisis económica mundial ha elevado, de manera muy significativa, el ejercicio de esta libertad en nuestro país, de tal manera, que se hace más necesario que nunca garantizar el efectivo y eficaz ejercicio de este derecho. Por todo ello, la violencia, el uso de la fuerza, o cualquier otro término que utilicemos, que se oponga a la paz y tranquilidad social en el ejercicio del derecho de reunión, no tiene cabida en nuestra norma fundamental de convivencia. En este trabajo nos preguntamos:

¿Qué motivación existe en estos sujetos para ejercer el uso de la violencia, en detrimento de muchas de las normas jurídicas y sociales que imperan en nuestra sociedad, en lugar de utilizar otras alternativas posibles?, ¿qué razones pueden justificar este tipo de conductas violentas?, ¿el uso de la violencia es una elección libre o se trata de una conducta irracional producto de una despersonalización en el interior de la masa?

Este estudio pretende aportar un mayor conocimiento sobre la libertad de reunión. Trataremos de ahondar en su realidad, conocer sus intereses en conflicto, los problemas que

\footnotetext{
${ }^{1}$ Programa de Doctorado en Derecho y Ciencias Sociales, UNED. Dirigido por el Dr. D. Alfonso Serrano Maíllo.
} 
plantea su ejercicio, la aparición del fenómeno de los comportamientos delictivos violentos en las reuniones y manifestaciones, así como aproximarnos a los sujetos titulares individuales de esta libertad, mediante un método de análisis cualitativo, que permita explorar y explicar la realidad tal como la experimentan sus protagonistas.

Palabras claves: Derecho de reunión, teoría de la neutralización, legitimación, violencia.

\section{Abstract}

The right of assembly is an extremely current socio-legal reality, since its practice is becoming more and more part of everyday life in democratic countries. The world economic crisis has significantly increased the practice of this right in our country, making it more necessary than ever to warrant the effective and efficient practice of this right. This means that violence, force or any other similar term, that jeopardizes peace and social calm during the practice of this right, has no place in our fundamental regulation of coexistence. We ask in the present paper:

For what reasons do these subjects exercise the use of violence, at the expense of many legal and social regulations that prevail in our society, instead of other alternatives? How can they justify this kind of violent behaviour? Is the use of violence a question of free choice or is it an irrational behaviour caused by depersonalization when the subject forms part of a group?

In this study we would like to point out some of these questions. This study claims to increase the understanding of the right of assembly and demonstration, and in the appearance of the phenomenon of violent criminal behaviour during gatherings and demonstrations.

Finally, we will approach the individual entitled subjects of this right, by means of a qualitative analysis, that will allow us to explore and explain the reality in the way its main subjects experience it.

Keywords: The right of assembly, neutralization theory, violence and legitimacy

\section{Sumario}

1. Introducción.

2. Las Técnicas de neutralización: enfoque teórico.

3. Estudio empírico.

\subsection{Metodología.}

\subsection{Codificación.}

3.3 Familias de códigos: categorías.

4. Mapas relacionales.

5. Resultados. 


\section{Conclusiones.}

7. Bibliografía

\section{INTRODUCCIÓN}

No existe en los sistemas de ordenación del conocimiento, (AENOR, clasificación Decimal Universal, 2004 ; UNESCO, Tesauro, 2008), un acuerdo académico sobre su conceptualización, usos, jerarquía, etc. del concepto de violencia. Debido a ello, la violencia objeto del interés criminológico de nuestra propuesta de investigación, se basa en una delimitación pragmática, de manera que su significado, debe inferirse de la realidad social y jurídica imperante en un territorio concreto y en un momento histórico determinado. Acorde con este criterio entenderemos como violentas o que incitan a la violencia:

Aquellas acciones $u$ omisiones, directa o indirectamente ejercidas contra seres vivos o cosas, mediante una manifestación física, verbal o psicológica, y con un ánimo tendencial ofensivo desviados de la norma social, relevantes para el derecho penal o el administrativo sancionador que alteran o pueden alterar total o parcialmente el libre y normal ejercicio del derecho de reunión.

\section{LAS TÉCNICAS DE NEUTRALIZACIÓN: ENFOQUE TEÓRICO}

El punto de partida de nuestra investigación es el "individuo social", entendido como el sujeto integrante de un grupo social superior, al que llamamos sociedad. La sociedad tratará de moldear su conducta en determinados aspectos para convertirlo en un "individuo adaptado socialmente", pero sin hacerle perder su individualidad en su proceso de toma de decisiones, al que se verá sometido constantemente y por el que llegado el caso se le exigirá una responsabilidad individual.

¿Cómo se justifican las acciones violentas en el ejercicio del derecho de reunión en España? ¿Cuáles son los motivos que conducen a personas socialmente adaptadas a desviarse de la norma?

Sykes y Matza (Sykes, G.M. , Matza, D. 1957) tratan de explicar como funcionan los procesos que permiten, que un individuo sometido a unos métodos socializadores decida apartarse de la norma socialmente aceptada, aún incluso, a sabiendas de que no está haciendo lo correcto. Estas causas que funcionan como una justificación de los comportamientos contrarios a las normas, serán agrupadas y englobarán las llamadas "técnicas de neutralización" , rebajando o incluso suprimiendo el conflicto de intereses existente, y por consiguiente, atenuando o eximiendo de responsabilidad a nivel cognitivo. 


\section{ESTUDIO EMPÍRICO}

\section{1.- METODOLOGÍA}

Profundizando en la senda propuesta por Maruna y Copes ( Maruna y Copes, 2005) de superar la dicotomía entre las métodos de investigación cualitativos y cuantitativos, hemos adoptado una vía ecléctica fundamentada en el análisis sistemático de contenido, que nos permite obtener unos resultados basados en datos medibles y fiables, a la vez que ricos en inferencias cualitativas.

El medio más adecuado a nuestro objeto de estudio lo encontramos en Internet, en concreto en páginas de periódicos ("El Mundo", "El Diario" y "El Público"), donde se han establecido foros comunicativos abiertos a la participación colectiva, con el único límite del respeto a la ley, y donde los propios sujetos se expresan libremente. Se elimina el sesgo de querer proyectar una determinada imagen, al no conocer que sus respuestas serán observadas para su estudio. El análisis sistemático de contenidos se prolonga durante el período que comprende desde agosto de dos mil once, con los incidentes acontecidos durante las conocidas como las "marchas laicas", los movimientos del"15-M" $\mathrm{y}$ finaliza en enero del dos mil catorce con las situaciones generadas durante las protestas del "Gamonal".

Como herramienta de gestión para el análisis cualitativo de contenido se ha utilizado el software "ATLAS.TI", en su versión de desarrollo 6.0.

\subsection{CODIFICACIÓN}

A continuación, vamos a desarrollar el significado de los códigos generados.

1.- LEGÍTIMA DEFENSA (código "in vivo" ) . Dos características muy significativas aparecen en la descripción de este código, pues el código se constituye como una causa de justificación penal, y quizás por ello, es muy conocido y deriva del propio lenguaje de los actores. Ejemplo de las citas de los chats: "violencia para defenderse es legitima defensa, ya veis por donde se pasan las manifestaciones pacificas".

2.- LOCUS EXTERNO (código teórico) . Los sujetos manifiestan que no son libres a la hora de decidir y actuar, sino que sus decisiones son producto de factores externos que determinan sus acciones, y por tanto no se les debe hacer responsable de sus actos. Lo característico será la ausencia de voluntad hacia la violencia. Ejemplo de las citas de los chats: "Pero, no queremos tanta represión, porque con tanta represión, surgen personas que no la soportan y cometen actos que en lugar de favorecer las protestas, le dan carnaza al gobierno para justificar cargas policiales contra todo aquel ciudadano que protesta pacíficamente, ante tanta barbarie que éste gobierno viene haciendo desde que llegó al poder". 
3.- NO INTENCIONALIDAD O PRETERINTENCIONALIDAD (código teórico). El significado atribuido a este código presenta la peculiaridad de pertenecer al foro interno de pensamiento del sujeto, de tal manera que la existencia o no de intencionalidad se debe inferir de sus manifestaciones. Para el sujeto lo fundamental es que no quería ese resultado (la ausencia del elemento volitivo), de tal manera que el sujeto obtiene un resultado que no buscaba o que va más allá del elemento volitivo de su acción. Ejemplo de las citas de los chats: "El Policia es "amigo" de los delincuentes (pues son sus clientes habituales y hacen por llevarse bien) y "enemigo" del Pueblo que sale pacíficamente a Protestar".

4.- VICTIMISMO (código teórico). Las manifestaciones atribuidas en nuestra investigación a este código comprenden aquellas en la que los sujetos se perfilan como víctimas en la situación violenta, comprendiendo un amplio abanico de posibilidades de interpretarse como tales: manifestaciones de no haber cometido ninguna acción violenta, alegan que la violencia es la respuesta a una provocación previa, de tal forma que se trata de una situación querida pero se sienten que procede de una incitación previa (la diferencia con el código "legítima defensa" estriba en que en éste concurre un ataque o agresión previa y en el victimismo, todo lo más manifiestan una provocación, la cual no comprende un ataque violento previo). Ejemplo de las citas de los chats: "¿esto extraña a alguien? es la vía normal que emplean para dar palos, los infiltrados policiales son los que empiezan a provocar".

5.- DAÑO FÍSICO (código sustantivo) . El sujeto manifiesta que la violencia no ha generado ningún tipo de menoscabo corporal en ninguna persona, ni en bienes materiales o patrimoniales. El daño corporal se entiende como el menoscabo o reducción de la utilidad de la integridad física. Respecto a el daño material o patrimonial, incluiría la pérdida o disminución de utilidad de la cosa, que puede ser reparada con otros bienes o con dinero en concepto de indemnización. La creencia o manifestación de la inexistencia de un daño físico, material o patrimonial, o de una entidad insignificante, favorece el equilibrio del sentimiento de culpa y facilita la aceptación de la violencia. Ejemplo de las citas de los chats: "En el último año y medio habré asistido a unas 50 manis y puedo decir categóricamente de que NUNCA he visto a ningún policía herido, NUNCA JAMÁs. Pero es que además es de puro sentido común".

6.- DAÑO MORAL (código teórico). El significado que se le atribuye a este código se fundamenta en los casos en los que el sujeto manifiesta que la violencia no ha generado ningún tipo de menoscabo o reducción de la utilidad espiritual de las personas. Este código se ha establecido como cajón de sastre de los daños para cuando no se codifique como daño físico. Ejemplo de las citas de los chats: "A mi me da la risa cuando leo que han habido varios policías heridos. Pero vamos a ver...¿ं.vosotros habéis visto como van vestidos y blindados? La única herida que pueden hacerse es si un compañero suyo se le va la mano y los golpea sin querer en medio de la carga, porque es casi imposible hacerles algún daño. ¿Se han roto una uña con la porra".

7.- CASTIGO (código teórico). El significado atribuido a este código se fundamenta en la creencia de que la violencia cumple la finalidad de castigar al que la recibe, basada en causas 
que suelen tener una relación directa o indirecta entre el castigador y la víctima. Ejemplo de las citas de los chats: "Cuando eso pase, algunos dirán que es intolerable, otros pensaremos que donde las dan, las toman".

8.- VÍCTIMA DEBILITADA (código teórico). En este código, hemos dotado de significado aquellas situaciones en las que la víctima está ausente, es desconocida o abstracta, lo que debilita su conciencia de incumplimiento social y facilita la comisión delictiva (el diagnóstico diferencial con el código "castigo" encuentra su base en el reconocimiento de un sujeto que sufre las consecuencias de la violencia, mientras que en el código "víctima debilitada" de sus manifestaciones parece que el sujeto no reconoce que la violencia la sufra ningún sujeto Ejemplo de las citas de los chats: "El pueblo paga y por eso puede quemar los contenedores iiSon suyos!!!

Por eso, también puede romper los escaparates de los bancos pues han robado a la población española 40 mil millones de euros, lo que significa que también esos escaparates son de los que los destrozan".

9.- PODER POLÍTICO DESLEGITIMADO (código “in vivo”). El sujeto manifiesta que el poder político carece ya de validez o legitimidad para imponer sus criterios políticos en la vida social y política y por tanto la violencia encuentra su justificación en la necesidad de luchar por unos objetivos determinados que ya no puede solucionar el poder político. Ejemplo de las citas de los chats: "Que salga en las noticias del mundo entero que en España el gobierno dictatorial expolia al pueblo en beneficio de las oligarquías y manda a los esbirros a machacarlo a golpes cuando sale a la calle a pedir el fin de la opresión. Hasta el final. La recompensa es grande : derribar con estrépito este desgobierno ilegítimo y traidor, al servicio del poder económico, decidido a terminar con todos los avances sociales conseguidos durante más de un siglo. Ni un paso atrás".

10.- VIOLENCIA DE ESTADO (código "in vivo"). Los actores expresan que las diferentes medidas que haya tomado el Estado son "violencia del Estado", es decir, uso de la fuerza política, social o legal no amparado en los derechos humanos internacionalmente reconocidos (el diagnóstico diferencial con el código "legítima defensa" se establece en base al criterio especial de fuerza que vulnera los derechos humanos y que va más allá de una defensa legítima). Ejemplo de las citas de los chats: "Si hay violencia de Estado hay que responderles con la misma moneda".

11.- CAMBIO DE REFERENCIAS (código teórico). Este código se explica porque el sujeto manifiesta, ya lo haga expresamente o deba deducirse de sus palabras, que la violencia deriva de una situación de disconformidad social, pues existe otra necesidad diferente a la socialmente esperada (se incluyen los supuestos de defectuosa socialización). Ejemplo de las citas de los chats: "No le gustan los medios, pero sí los fines, luego el fin justifica los medios. La protesta del Gamonal no tiene nada que ver con la corrupción, ni contra "los políticos" sino contra las obras del bulevar. Al justificar la turba violenta con abstracciones con las que todos 
estamos de acuerdo (¿Quién no está de acuerdo en combatir la corrupción y los excesos de los políticos?)".

12.- COMPAÑERISMO (código "in vivo"). El sujeto manifiesta que el ejercicio violento es fruto de un sentimiento de pertenencia y lealtad a un grupo (compañeros), que se convierte en referente y por tanto la motivación o interés de la violencia adquiere una dimensión colectiva o grupal aunque se realice de manera individual. Ejemplo de las citas de los chats: "Ánimo compañeros!! El pueblo unido, jamás será vencido!".

13.- BENEFICIO MATERIAL O ECONÓMICO (código teórico). La argumentación a favor de la violencia encuentra su fundamento en el supuesto resultado económico favorable. Se incluirá por tanto la pretensión de un beneficio a corto, medio y largo plazo, sin ningún tipo de restricción temporal (la única matización hemos de realizarla en relación a la intención derivada de sus propias manifestaciones de obtención de un beneficio político, pues en este caso integrará el código "cambio político"). Ejemplo de las citas de los chats: "La conclusión es lógica la diga Agamenón o su porquero. La violencia es efectiva y rentable si consigue detener un proyecto público en una democracia, ya sea asesinando para parar la central nuclear de Lemóniz, o destruyendo el mobiliario urbano y quemando los contenedores que pagamos todos".

14.- CAMBIO POLÍTICO (código teórico). Los sujetos manifiestan que la violencia supone una necesidad para que se tomen determinadas decisiones políticas que supongan un cambio. La referencia al cambio político presenta un amplio espectro de contenido, pues incluye cualquier cambio de tendencia en determinadas políticas, como a un cambio político de mayor calado, por ejemplo el cambio de partido político en el gobierno, de políticas gubernamentales estatales, regionales, locales, etc. Ejemplo de las citas de los chats: "La recompensa es grande : derribar con estrépito este desgobierno ilegítimo y traidor, al servicio del poder económico, decidido a terminar con todos los avances sociales conseguidos durante más de un siglo. Ni un paso atrás".

15.- PLACER (código teórico). Este código presenta la particularidad de recoger aquellos supuestos en los que los sujetos manifiestan que la violencia les da gusto, les agrada sienten satisfacción al ejercerla (el diagnóstico diferencial que hemos establecido con el código "tensión e ira" se basa en que los sujetos expresan un estado de oposición u hostilidad latente entre personas, clases, grupos humanos, etc. Si en el código placer lo fundamental es que el sujeto la aprecia como satisfactoria, la inclusión en el código "tensión e ira" añade un plus de exaltación, indignación, saña, encono o deseo de venganza. Ejemplo de las citas de los chats: "Como me gustaría ser un policía de estos y soltar unas cuántas ostias a toda esta gentuza...".

16.- TENSIÓN E IRA (código teórico). En este supuesto el sujeto manifiesta una liberación de la frustración interior, consciente o inconscientemente, voluntaria o involuntariamente a través de la violencia, manifestada o no hacia el exterior, pues subyace 
un estado de oposición, indignación, enojo u hostilidad latente. Ejemplo de las citas de los chats: "Hay que descargar la rabia contenida de alguna manera".

En este punto de la investigación queremos hacer mención a la posible existencia de una motivación que pudiera favorecer o facilitar el surgimiento o mantenimiento de la violencia. Ésta se configura mediante los cuatro últimos códigos expuestos, que bajo unos criterios de flexibilidad y de interpretación extensiva puedan integrar las posibles motivaciones e intereses que manifiesten los sujetos sobre la violencia. A estas áreas de amplio contenido, de modo genérico las vamos a llamar códigos motivacionales por tratar de explicar más específicamente las justificaciones de la violencia, aunque cada una de ellas integrará un código específico.

\section{Frecuencia de los códigos justificativos y motivacionales}

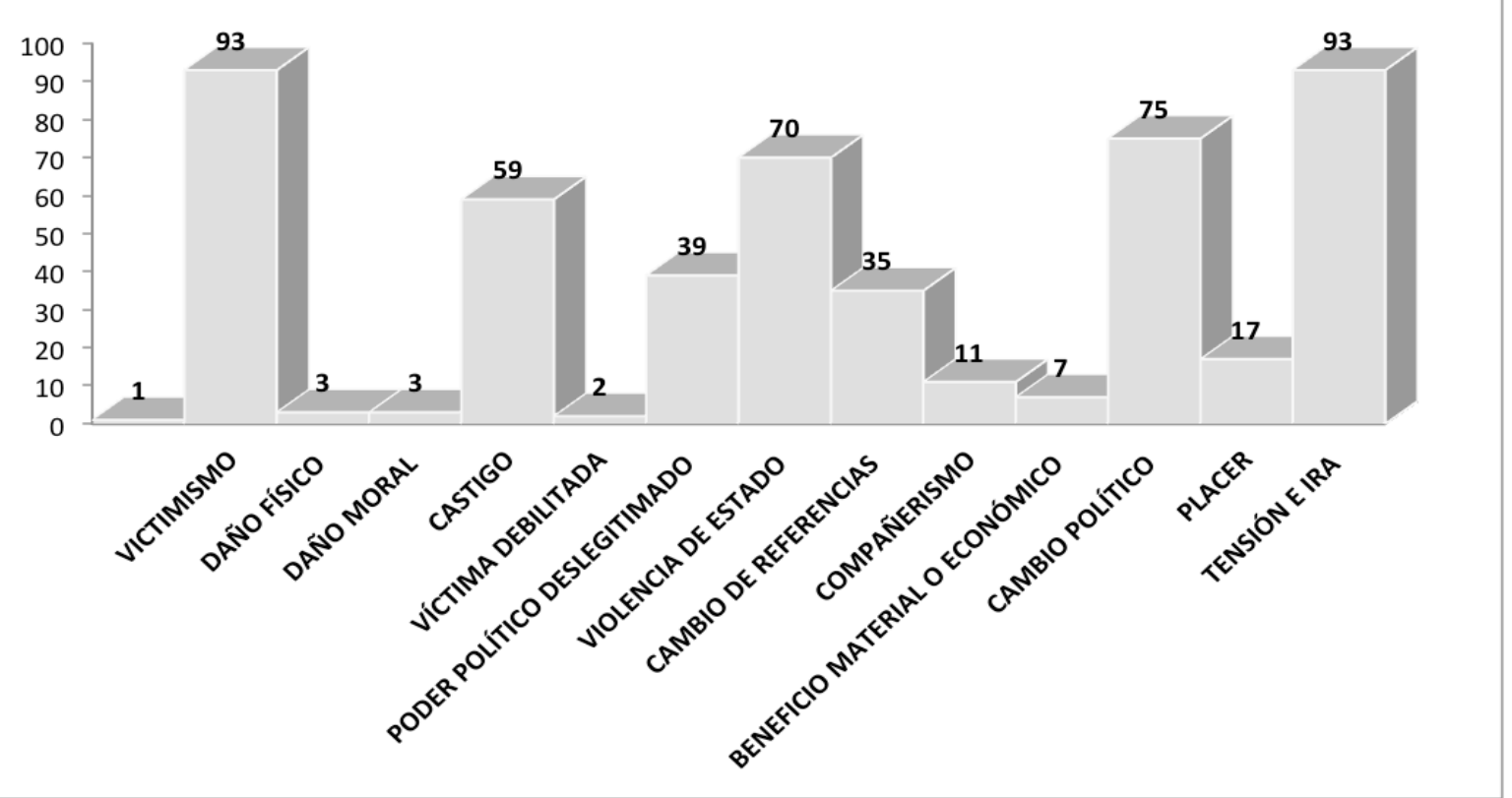

Ilustración 1. Frecuencia absoluta de los códigos.

Los resultados muestran tres códigos justificativos que sobresalen del resto: el "Victimismo" es el código que más veces se extrae de las citas, la "Violencia de Estado", y el tercero el código "Castigo" con un total de cincuenta y nueve veces. Los códigos motivacionales (se presentan en color rojo) denotan una manifestación de una mayor riqueza para una interpretación motivacional y no meramente justificativa de la violencia.

La "Tensión e ira" y el "Cambio político" han sido muy recurrentes por los sujetos activos, destacando sin embargo por su escaso uso, los códigos obtención de un "Beneficio material o económico" y el "Placer". 


\subsection{FAMILIAS DE CÓDIGOS (CATEGORIAS).}

La utilidad del análisis de contenido para ahondar en la explicación de un fenómeno previamente analizado y la integración de los códigos obtenidos en categorías o familias centrales ha presentado un resultado interesante en nuestra investigación. El proceso de abstracción generador de los códigos y las categorías o familias, ha tenido en cuenta las técnicas de neutralización como base de conocimiento teórico no vinculante, de tal modo, que han surgido códigos y categorías ya propuestas por Sykes y Matza (1957), como otros de nueva generación. Las categorías que representan un patrón de conducta, para nosotros será un patrón cognitivo o de conducta, de tal manera que lo principal será la manifestación que verbalizan sobre la violencia, aún cuando físicamente no sean los que realicen los actos violentos. Las categorías centrales surgidas de los códigos se exponen a continuación:

1.- Negación de la responsabilidad. La presente técnica de neutralización expuesta por Sykes y Matza (1957) se caracteriza porque el sujeto no se considera responsable de la violencia. Esta auto-exculpación permite mitigar sus propios sentimientos de incongruencia y la desaprobación social generada por su actuación. La comisión delictiva será fruto de las circunstancias accidentales que rodean al sujeto activo y de las cuales carece de culpa y de responsabilidad.

En nuestra investigación se han integrado en ella los siguientes cuatro códigos ya expuestos: Legítima defensa, Locus de control externo, No intencionalidad o preterintencionalidad y Victimismo.

2.- Negación del daño. La técnica "negación del daño" supone la ruptura del vínculo entre la acción y sus consecuencias. El comportamiento violento se justifica fácilmente, puesto que se alega la inexistencia o irrelevancia del daño y de esta forma no se entiende que se haya causado un mal irreparable a la víctima, ni a la sociedad. En nuestra investigación los siguientes códigos conforman esta categoría de negación del daño: Daño físico y Daño moral.

3.- Negación de la víctima. Sykes y Matza argumentaban que esta técnica permitía al sujeto activo no solo no otorgar a la víctima dicha consideración, sino que también, debía soportar la acción delictiva y el resultado de la misma. En nuestra investigación los códigos que integran esta categoría son: Castigo y Víctima debilitada.

4.- Condena a quien condena. Mediante esta técnica, los sujetos manifiestan que los encargados de valorar, reprimir o juzgar la violencia, han perdido la autoridad para hacerlo. Nuestro análisis incluye los siguientes dos códigos dentro de esta categoría: Poder político deslegitimado y Violencia de Estado.

5.- Apelación a una lealtad superior. La existencia de un conflicto de intereses puede impulsar la justificación de la violencia a favor de un interés superior. Los siguientes códigos integrarán esta categoría: Cambio de referencias y Compañerismo. 
6.- Motivación hacia la comisión delictiva. Una de nuestras hipótesis de trabajo consiste en tratar de encontrar un objetivo, una finalidad en el ejercicio de la violencia, en caso de que ésta exista. Los siguientes códigos han configurado esta categoría: Beneficio material o económico, Cambio Político, Placer y Tensión e Ira.

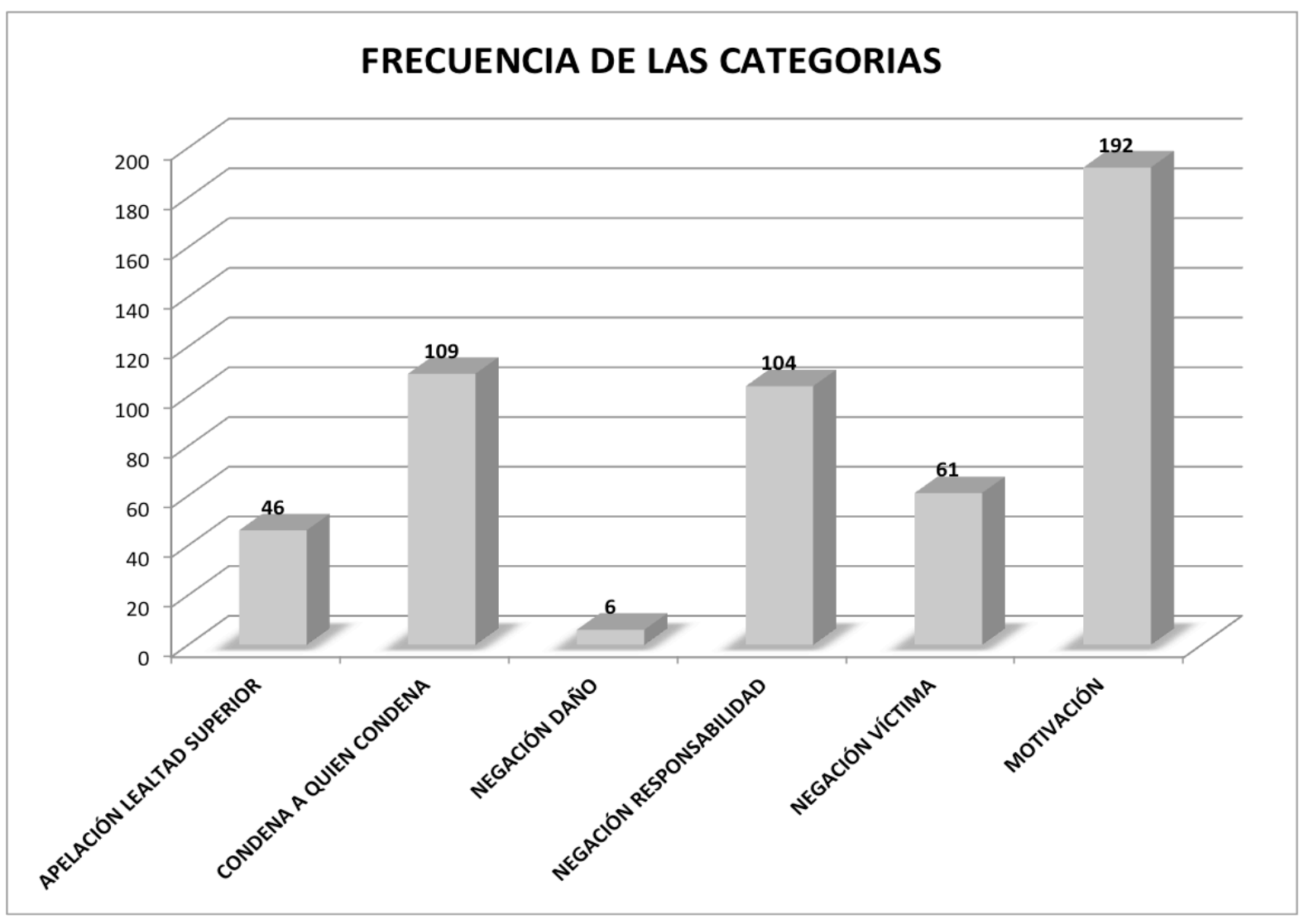

Ilustración 2. Frecuencia absoluta de las categoría

\section{4.- MAPAS RELACIONALES}

Además de la frecuencia de aparición de los códigos, se ha observado la concurrencia de varios de ellos en una misma cita, de manera que se han usado conjuntamente como argumento con carácter de excusa del ejercicio de la violencia. Se expondrán a continuación, en el mismo orden anterior, las concurrencias descritas, integrando el mapa de relaciones entre códigos. Para ello, deconstruiremos los códigos dotándolos de significado y crearemos una estructura compleja, compuesta por la suma de los significados asignados a cada código, tratando de obtener un argumento o pensamiento complejo aducido por el individuo-actor.

Vamos a definir las relaciones complejas entre códigos (mapas de relaciones complejas entre códigos), como el proceso de unión de varios códigos formando un discurso argumentativo usado por los individuos-actores para neutralizar su conducta, siempre que se cumplan los siguientes requisitos: primero una estructura conformada por la conjunción de 
un mínimo de tres códigos y segundo una frecuencia de aparición de un mínimo de dos ocasiones. Ejemplo: VICTIMISMO+VIOLENCIA DE ESTADO+TENSIÓN E IRA:"Voy a ejercer la violencia (ex ante) o he ejercido la violencia (a posteriori), ya que soy una víctima de la violencia ilegítima del Estado con la finalidad de liberar mi frustración interior".

\begin{tabular}{|c|c|c|c|c|c|c|c|}
\hline \multicolumn{8}{|c|}{ FRECUENCIA ABSOLUTA DE CONCURRENCIAS } \\
\hline & NEG.RESP. & NEG.DAÑO & NEG.VICT & CONDENA & APELACIÓN & MOTIVAC & TOTAL \\
\hline NEG.RESP. & & 0 & 7 & 29 & 3 & 58 & 97 \\
\hline NEG.DAÑO & 0 & & 0 & 0 & 1 & 2 & 3 \\
\hline NEG.VICT & 7 & 0 & 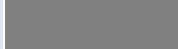 & 9 & 5 & 47 & 68 \\
\hline CONDENA & 29 & 0 & 9 & & 4 & 60 & 102 \\
\hline APELACIÓN & 3 & 1 & 5 & 4 & & 32 & 45 \\
\hline MOTIVAC & 58 & 2 & 47 & 60 & 32 & & 199 \\
\hline TOTAL & 97 & 3 & 68 & 102 & 45 & 199 & \\
\hline
\end{tabular}

Tabla 1. Frecuencia absoluta de concurrencias por categorías

\section{RESULTADOS}

Las verbalizaciones transcritas por los individuos-actores, en relación a las actuaciones violentas realizadas durante el ejercicio del derecho de reunión, permiten apreciar la argumentación de unas razones, que tratan de aportar una justificación al ejercicio de la violencia. Son recurrentes los comentarios, que tratan de buscar un sentido, una excusa, o una racionalización, al actuar violento cometido de forma individual o colectiva durante el desarrollo de la libertad de reunión.

Del total de datos analizados (7131 comentarios), se han seleccionado como comentarios objeto de interés para nuestra investigación un total de quinientas dieciocho citas (518 citas), lo que supone un $7,26 \%$ del total de comentarios realizados por los individuos-actores (la peculiaridad de nuestra investigación cualitativa y en el método de análisis sistemático de contenidos, al no contar con ninguna herramienta de dirección de las verbalizaciones, supone obtener unos datos que no han sido provocados por el investigador, aún cuando genere una muestra con un gran volumen de datos). Del total de comentarios de 
interés expuestos (518 citas), casi el sesenta y tres por cien de ellos recogían de modo libre, espontáneo y voluntario una referencia directa a una posible causa de justificación de los delitos cometidos (62,93\%). Además, se ha apreciado también la existencia de verbalizaciones que presentan una funcionalidad diferente a una posible excusa exculpatoria, pues de forma expresa y clara recogen un supuesto fin perseguido por la acción delictiva. Esta muestra, que supone un 37,06 \% del total de las citas, representa una motivación hacia la comisión delictiva.

Como hemos desarrollado con anterioridad, coincidimos con Matza (1957) en el determinismo suave, en base al cual, será el conjunto formado por las técnicas de neutralización y la motivación delictiva parte de la causa y parte de los efectos del delito. La finalidad perseguida por el delito activaría o facilitaría el uso de las técnicas de neutralización, tanto antes como después de cometida la acción delictiva, pues "ex antes" supone la necesidad que debe ser justificada y "a posteriori" la necesidad satisfecha que racionaliza mi comportamiento delictivo, o la necesidad no satisfecha que racionaliza mi comportamiento delictivo y justifica un nuevo intento, favoreciendo la persistencia .

Profundizando en los resultados se aprecia que los códigos que presentan una mayor frecuencia total son los denominados como "Victimismo" y "Tensión e ira", seguido de "Violencia de Estado" y "Cambio político" y que integran las técnicas Negación de la responsabilidad, Condena a quien condena y la categoría Motivación (integrada por el uso de verbalizaciones que contenían en sí mismas una finalidad, un objetivo claro que perseguía el delito).

Coincidimos en lo aportado por la investigación de Copes (2003), según la cual, casi el $60 \%$ de los delincuentes entrevistados usaron al menos una técnica de neutralización y un $24 \%$ usaron varias técnicas. Apreciaron también que no todas las técnicas fueron mencionadas y encontraron variaciones en las frecuencias, al igual que en los resultados aportados por Maruna y Copes (2005). De lo expuesto se desprende que entre los argumentos cognitivos más usados respecto a la retórica violenta en el derecho de reunión destacan:

1.- NEGACIÓN DE LA RESPONSABILIDAD + MOTIVACIÓN DELICTIVA (conformado por los siguientes códigos: VICTIMISMO + TENSIÓN E IRA):“Voy a ejercer la violencia (ex antes) o he ejercido la violencia (a posteriori), ya que soy una víctima y con la finalidad de liberar mi frustración interior".

2.- NEGACIÓN DE LA VÍCTIMA + MOTIVACIÓN NEGACIÓN DE LA RESPONSABILIDAD + MOTIVACIÓN 2.- NEGACIÓN DE LA VÍCTIMA + MOTIVACIÓN DELICTIVA (conformado por los siguientes códigos: CASTIGO + TENSIÓN E IRA):“Voy a ejercer la violencia (ex antes) o he ejercido la violencia (a posteriori), ya que la víctima se merece sufrir ese mal y con la finalidad de liberar mi frustración interior". 
3.- CONDENA A QUIEN CONDENA + MOTIVACIÓN DELICTIVA (conformado por los siguientes códigos: VIOLENCIA DE ESTADO + TENSIÓN E IRA):“Voy a ejercer la violencia (ex antes) o he ejercido la violencia (a posteriori), ya que existe una violencia ilegítima del Estado con la finalidad de liberar mi frustración interior".

Las técnicas que con más frecuencia aparecen relacionadas, y en orden decreciente serían: Condena a quien condena, Negación de la responsabilidad, Negación de la víctima, Apelación a una lealtad superior y por último Negación del daño. La categoría Motivación delictiva se presenta como la que más se relaciona.

Lo expuesto difiere de la visión de Cohen (2001), para quien la más representativa de las técnicas era la Negación de la responsabilidad. Podríamos decir, que en los delitos violentos cometidos en el ejercicio de reunión, la técnica Negación de la responsabilidad comparte esa preeminencia con la técnica Condena a quien condena. Estas frecuencias de apariciones difieren de las mencionadas en otras investigaciones ..

Especial comentario merece que la técnica "Condena a quien condena" sea la más utilizada, pues si la faceta de participación política "directa", su carácter público y subjetivo, son las principales características del derecho de reunión, de las técnicas propuestas por Sykes y Matza (1957), la única que presenta connotaciones políticas evidentes es la "Condena a quien condena", ya que en su base supone una ruptura con el pacto constitucional establecido en la más moderna etapa constitucional. Parece pues, que el espíritu que inspira la justificación de la violencia ejercida durante el desarrollo del derecho de reunión, comprende numerosas respuestas hacia unas argumentaciones justificativas de delitos con connotaciones políticas.

Junto a la técnica "Condena a quien condena", en la que como ya hemos expuesto subyace una relación de sometimiento desigual al imperio de la ley que convierte a una de las partes en víctimas del sistema, la técnica "Negación de la responsabilidad" ha sido la segunda más usada por la variable Victimismo, pues, aún sin esas connotaciones políticas, el sujeto considera que las conductas violentas surgidas derivan de una relación previa establecida por el victimario.

Integrando la categoría "Motivación a la violencia", el argumento del Cambio político (junto con la Tensión e ira), ha sido uno de los más usados, apoyando la tesis anterior, de la presencia de unas connotaciones políticas en las causas de justificación de las conductas violentas. Además de este argumento de cambio político (entendido como la voluntad de ejercer la violencia tratando de obtener unas decisiones políticas favorables para los autores), el más frecuentemente usado ha sido la necesidad de liberar la frustración interior del actor, su tensión e ira acumulada.

Además, se ha observado que las técnicas de neutralización y la motivación aparecen conformando unas estructuras relacionales complejas (integradas por la mezcla de códigos y de categorías), que trataban de aportar una explicación de los actos acontecidos. 
De la muestra analizada se deduce que el ejercicio de la violencia contra personas o bienes, cometido en el ejercicio del derecho de reunión, es percibido por los propios sujetos activos como una acción justa en base a los siguientes motivos, divididos en dos bloques:

El primer bloque, con una mayor frecuencia de alegación (65\% de frecuencia), lo conforman las técnicas: Condena a quien condena y Negación de la responsabilidad. Basan su justificación en la afirmación según la cual, las personas que deben juzgar el comportamiento desviado, no están en condiciones de hacerlo, pues han perdido su autoridad y legitimidad pues se presentan como autores delictivos previos, es decir, el poder ejecutivo del Estado es culpable de cometer delitos de Estado (a través sobre todo de la Policía como ejecutor).

En segundo lugar por muy poca diferencia, los actores se consideran que no son responsables, pues son las víctimas de actuaciones indebidas previas y por tanto reaccionan a una provocación previa de las autoridades. En la mayoría de los casos se trataba de provocación de la Policía o de directrices políticas que los victimizaban.

En el ejercicio del derecho de reunión, ambas técnicas presentan el paralelismo de establecer una relación de victimismo entre el sujeto que ha justificado el delito violento (la víctima) y el representante de la autoridad (victimario), aunque basada en percepciones diferentes, según las diferentes justificaciones aducidas (a modo de ejemplo: víctima, individual o colectiva, directa o indirecta, de la violencia subjetiva del Estado, víctima, individual o colectiva, directa o indirecta, de la obediencia debida a un poder político subjetivamente deslegitimado, etc.).

El segundo bloque, con una frecuencia de utilización del 33\% del total, lo integran las dos siguientes técnicas: "Negación de la víctima" y "Apelación a una lealtad superior". En la primera de ellas, un argumento muy recurrente ha sido el merecimiento de un sufrimiento por las víctimas, representadas en la mayoría de los casos por la Policía, como brazo ejecutor de la represión derivada de la autoridad. La técnica "Apelación a una lealtad superior", en contra de lo que pudiera parecer, no ha destacado por la frecuencia del código compañerismo, mediante la alegación de unos vínculos superiores entre personas, sino por el código cambio de referencias, que presenta un argumento menos subjetivo y personal, caracterizado por la búsqueda de nuevos patrones de seguimiento, que justificarían incluso la comisión de acciones violentas.

\section{CONCLUSIONES}

De nuestra investigación se aprecia el uso recurrente de las técnicas "Condena a quien condena" y "Negación de la responsabilidad" en el ejercicio del derecho de reunión, reduciendo el escenario a una relación de victimismo bilateral, en la que la autoridad representa un rol de víctima provocadora, y el delincuente de víctima provocada.

Por otro lado, aún no habiendo podido extraer respuestas concluyentes respecto al favorecimiento del delito mediante el uso por el delincuente de las técnicas de neutralización, 
creemos que la neutralización puede jugar un papel importante en la facilitación del discurso violento, su persistencia o desistimiento. Además, el que los comentarios en los chats no sean aportados por los autores de la violencia y que se hagan de manera coetánea a la producción de los hechos, nos introduce de lleno en lo que vamos a llamar la neutralización solidaria.

Ésta se traduce en el favorecimiento de la aparición de la retórica violenta mediante el uso de las técnicas de neutralización, a través de un aprendizaje por imitación. Lo decisivo radica en que el sujeto justifica la conducta delictiva del modelo descargándole de culpa, a la vez que le dota de un motivo subjetivo que explica su comisión delictiva y lo comparte. Factor decisivo será también el refuerzo o el castigo conductual derivado del modelo.

Todo ese proceso de argumentación cognitiva, creemos que facilita la reproducción en los tres niveles expuestos por Bandura y Walters (1988), y por tanto, favorecería la predisposición a la comisión delictiva en el sujeto que realiza la neutralización solidaria, mediante un proceso de aprendizaje basado, entre otras, en la asociación diferencial indirecta defendida por Akers (1985). Las neutralizaciones realizadas con posterioridad al acto delictivo favorecerían el desistimiento o la persistencia delictual.

\section{BIBLIOGRAFÍA}

Agnew, R. (1994). The Techniques of Neutralization and Violence. Criminology. 32.

Akers, R.L. (1985). Deviant Behavior: A Social Learning Approach. Belmont, CA: Wadsworth.

Bandura, A., Walters, R.H. (1988). Aprendizaje social y desarrollo de la personalidad. Madrid: Alianza Editorial.

Cohen, S. (2001). States of Denial: Knowing About Atrocities and Suffering. Cambridge, Reino Unido: Polity Press.

Copes, H. (2003). Societal Attachments, Offending Frequency, and Techniques of Neutralization. Deviant Behavior 24:101-127.

Copes, H., Vieraitis, L., Jochum, J. (2007). Bridging the Gap Between Research and Practice: How Neutralization Theory Can Inform Reid Interrogations of Identity Thieves. Journal of Criminal Justice Education v.18:444- 459.

Cressey, D. R. (1953). Other people's money: a study in the social psychology of embezzlement. Glencoe, IL: Free Press.

Hirschi, T. (1969). Causes of Delinquency. Berkeley: University of California Press.

Maruna, S., Copes, H. (2005). Excuses, Excuses: What have we learned from five decades of neutralization researches? Crime and Justice: A review of research. № 32. Págs. 221320.University of Chicago Press. 
Minor, W.W. (1981). Techniques of neutralization: A reconceptualization and empirical examination. Journal of research in Crime and Delinquency. № 18. Págs. 295-318.

Serrano Maíllo, A. (2009). Introducción a la Criminología. (6o Ed). Madrid: Dykinson.

Sykes, G.M, Matza, D. (1957). Techniques of Neutralization: a Theory of Delinquency. American Sociological Review. № 22. Págs. 664-673.

Topalli, V. (2005). When being good is bad: An expansión of neutralization theory. Criminology. №. 43. Págs. 664-670. 